\title{
Microbiological Quality of Blister Pack Tablets in Community Pharmacies in Jordan
}

\author{
Qasem M Abu Shaqra ${ }^{1}$, Maissa T Shawaqfah ${ }^{2}$ and Walid Al Momani ${ }^{2}$ \\ 1Consultant Microbiologist, Jordan Medical Solutions Manufacturing Company, Zarqa, 2Department of Allied Medical Sciences, \\ Zarqa University College, Al- Balqa Applied University, Jordan.
}

*For correspondence: Email: qabushaqra@hotmail.com; Tel: 0095279 5009808; Fax: 0096253826883

\begin{abstract}
Purpose: To investigate the microbiological quality of blister-packed tablets manufactured and marketed in Jordan in order to assess Good Manufacturing Practice by pharmaceutical industries in the country.

Methods: A total of 66 items of 22 registered blister-packed tablet brands were purchased from community pharmacies in Amman. All the items were investigated for total bacterial count and the presence of specified microorganisms using compendial procedures.

Results: Out of 66 items purchased, forty eight (72.7 \%) products were free from microbial contamination, while 11 (16.7\%) harbored bacteria in counts < 102 cfu/g. The remaining 7 (10.6 \%) items contained counts between 102 and < $103 \mathrm{cfu} / \mathrm{g}$. The most commonly encountered contaminant was Bacillus species but specified objectionable bacteria such as Escherichia coli and Staphylococcus aereus were not detected. Aspergillus and Penicillium species were isolated in low numbers from few products. Six of the products with the highest stratified bacterial count were manufactured by one company and were also found to be contaminated with Aeromonas species.

Conclusion: This study demonstrates that blister-packed tablets produced by Jordanian pharmaceutical companies are within acceptable microbiological quality but the detection of microbial load in some brands close to the maximum allowable limit suggests the need for better adherence to GMP in the country.
\end{abstract}

Keywords: Blister pack, Community pharmacy, Good Manufacturing Practice, Microbial contamination, Quality control, Tablets

Tropical Journal of Pharmaceutical Research is indexed by Science Citation Index (SciSearch), Scopus, International Pharmaceutical Abstract, Chemical Abstracts, Embase, Index Copernicus, EBSCO, African Index Medicus, JournalSeek, Journal Citation Reports/Science Edition, Directory of Open Access Journals (DOAJ), African Journal Online, Bioline International, Open-J-Gate and Pharmacy Abstracts

\section{INTRODUCTION}

Oral dosage forms including tablets are not required to be sterile, but certain quality control measures are essential to keep the microbial content of these preparations safe and acceptable [1]. The extent of microbial contamination in tablets is usually influenced by the microbiological quality of the starting raw materials, packaging materials, personnel that come in contact with the product during the manufacturing process and the production environment as well as equipment. Failure to observe Good Manufacturing Practice (GMP) at any stage of production may consequently affect the microbiological quality of the product. Contaminants entrapped into the product via the above mentioned routes may not survive for a long period of time due to the lethal effect exerted by the various methods used in tablet production [2].

A recent survey carried out in Egypt [3] demonstrated that microbial contamination of 
tablets was the lowest of all non-sterile pharmaceutical preparations. However, alarming figures of tablets microbial load appeared in other publications [4-6]. High contamination levels were detected in tablets distributed by industries in containers and then dispensed to patients by counting.

In Jordan, marketed tablets are mostly packed in blisters. Hence, microbial contamination of these products is unlikely to occur after the packaging step in the manufacturing facility. High levels of microbial contamination in blister-packed tablets may indicate irregularities in the implementation of GMP standards by manufacturers. The objectives of this study were, first to investigate the microbiological quality of tablets manufactured and marketed in Jordan, and then to apply the results obtained to extrapolate the degree of pharmaceutical companies' adherence to GMP requirements in the country.

\section{EXPERIMENTAL}

\section{Materials}

Twenty two different brands of tablet dosage forms that contained 8 pharmaceutical active ingredients were randomly purchased from community pharmacies with preference for formulations with high public demand such as metformin, glibenclamide, acetylsalicylic acid and diclofenac salts. All purchased items were manufactured by companies registered in Jordan and their drugs approved by the Jordan Food and Drug Administration (JFDA). For each brand, 3 Paks with different batch numbers were obtained. Each purchased item was inspected for the information disclosed on the container label, including amount of active ingredients, manufacture date, and expiry date as well as batch number.

\section{Isolation of specified organisms}

The blister of each brand was wiped with $70 \%$ alcohol, and with the aid of a sterile scalpel, 5 tablets were taken and placed in a conical flask containing $50 \mathrm{ml}$ Tryptic Soya Bean Digest (TSBD) broth. The flasks were incubated at 35 ${ }^{\circ} \mathrm{C}$ in a shaking water bath for 48 hours before $1.0 \mathrm{ml}$ aliquots of the flask content were processed for the isolation of $E$. coli, Pseudomonas aeruginosa, Staphylococcus aureus and Salmonella species as described in the United States Pharmacopoeia [1].

\section{Microbial count}

Tablets were taken from the blister pack of each purchased item separately as described above, crushed in a mortar under aseptic conditions before $1 \mathrm{~g}$ was added to $9 \mathrm{ml}$ sterile phosphate buffer $\mathrm{pH}$ 7. The content of each tube was shaken vigorously for 2 min using a vortex mixer then allowed to stand for 30 minutes. One $\mathrm{ml}$ aliquot of each tablet supernatant was 10-fold serially diluted using similar buffer and kept in a standing position for additional 30 minutes. Aliquots of $1.0 \mathrm{ml}$ of each dilution were separately transferred into Petri dishes and the traditional pour plate technique was performed using TSBD agar. After 48 hours of incubation at $35^{\circ} \mathrm{C}$, developed colonies were counted and 5 of the grown colonies with apparently different colonial morphology were purified for further identification. Isolation and enumeration of yeast as well as molds was carried out by spread plate technique on Sabouraud's Dextrose agar supplemented with chloramphenicol as a bacterial inhibitor. Plates in this case were incubated at $27{ }^{\circ} \mathrm{C}$ for 2 weeks but because yeasts grow faster than molds, counts for the former organisms were performed during the first 3 days of incubation. The phosphate buffer used for microbial count and media employed were supplemented with $0.5 \%$ polysorbate 80 as well as $0.5 \%$ lecithin as neutralizing agents for preservatives, in case the tablets under study had been preserved. All media used in this investigation were the products of Difco, USA

\section{Identification of isolates}

Purified bacterial colonies recovered from contaminated samples were identified according to the diagnostic tables given by Barrow \& Feltham [7]. Tests performed for this purpose include Gram reaction, shape, carbohydrate utilization, catalase production, oxidase test, Indole production, spore formation, methyl red, Voges Proskauer, nitrate reduction, starch hydrolysis, tryptophan hydrolysis, hydrogen sulfide production, and citrate utilization.

\section{Neutralization efficacy}

Sterile phosphate buffer solution was supplemented with $0.5 \%$ methyl and $1 \%$ propyl parabens. After heating to dissolve, the solution was brought to room temperature and then challenged with $P$. aeruginosa ATCC 9027 to give a count of $103 \mathrm{cfu} / \mathrm{ml}$. Inoculums' standardization was performed using McFarland solution and spectrophotometry. One $\mathrm{ml}$ of the challenged sample was diluted with $9 \mathrm{ml}$ phosphate buffer amended with $0.5 \%$ polysorbate 80 as well as $0.5 \%$ lecithin. After half an hour, a further 10-fold serial dilution using similar buffer was made. All dilutions were kept at room temperature for additional $30 \mathrm{~min}$ to 
allow preservative neutralization to occur. Recovery of at least $50 \%$ of the inoculated bacteria on SBCD agar indicated the effectiveness of the neutralization process.

\section{Statistical analysis}

In order to determine batch to batch variation in the numeric data obtained for the 3 packs purchased for each brand, statistical analysis to establish the deviation from the mean count was carried out using t- test with the aid of Sigma Plot software. Differences were considered as statistically significance at $p<0.05$.

\section{RESULTS}

Visual inspection of all items purchased indicated that all were neat and un-tampered. Information disclosed on the containers included manufacturing date, expiry date, batch number and concentration of active ingredient in addition to cautions that the product was a drug. All tablets tested were smooth, without any unusual discoloration or indications of surface microbial contamination.

The results presented in Table 1 demonstrate that out of 66 items investigated, 48 (72.7\%) were free from microbial contaminants whereas the remaining 18 items (27.3\%), harbored bacteria in levels below $103 \mathrm{cfu} / \mathrm{g}$. It is evident from the same table that only $10.6 \%$ of the items contained bacterial count between 102 and 103 $\mathrm{cfu} / \mathrm{g}$. Three units with different batch numbers were analyzed for each brand and as table 1 shows; the highest contamination level appeared predominantly in the triplicate items obtained for one brand of metformin and another of acetylsalicylic acid. Both brands were manufactured by the same company.

Table 2 shows the types of microorganisms isolated from each product category. It is clear that Bacillus spp was the most commonly encountered Gram positive bacteria followed by Staphylococcus spp, while Aeromonas spp were the only Gram negative bacteria recovered. Filamentous fungi were present among the contaminants and were represented by Aspergillus as well as Penicillium spp but Candida spp were not detected. Both fungal species were recovered in very low numbers which were difficult to enumerate in a reproducible manner. It is important to mention that fungi were recovered from products regardless of the bacterial count detected. Table 3 provides information regarding the frequency of detection for different microorganisms in relation to the number of items in which they occurred.

Statistical analysis of the bacterial counts obtained indicated that batch to batch variation in the microbiological quality was detected for the products of two companies. This was deduced

Table 1: Extent of microbial count of blister packs

\begin{tabular}{lcccc}
\hline Brand/Active ingredient & No of units studied per brand & $\begin{array}{c}\text { Contaminated } \\
\text { units (\%) }\end{array}$ & \multicolumn{2}{c}{$\begin{array}{c}\text { Level of bacterial } \\
\text { Contamination/g (\%) } \\
<102\end{array}$} \\
\hline 102-< 103
\end{tabular}

Table 2: Types of microbial contaminants isolated from each brand type

\begin{tabular}{lcl}
\hline Brand/Active ingredient & No. of units studied in each brand & Microorganisms isolated \\
\hline Metformin & 12 & Bacillus spp, Molds*, Aeromonas spp \\
Glibenclamide & 6 & Staphylococcus spp, Molds* \\
Acetylsalicylic acid & 12 & Bacillus spp, Molds*, Aeromonas spp \\
Diclofenac salt & 9 & Bacillus spp, \\
Lovastatin & 6 & None \\
Chlorpheniramine & 9 & Staphylococcus spp, Bacillus spp, \\
lbuprofen & 6 & None \\
Multivitamins & 6 & Molds*, Staphylococcus spp \\
\hline${ }^{*}$ Aspergillus and/or Penicillium & &
\end{tabular}


from the variation noted on the bacterial count of tablets derived from 3 containers with different batch numbers. The deviation of counts from the mean was statistically significant at a probability level of $<0.05$. Preservative neutralization test indicated the effectiveness of the neutralizers used as it was always possible to isolate at least $50 \%$ of the challenge bacterium used in the test

Table 3: Frequency of contaminants isolated from the tablet brands studied.

\begin{tabular}{ll}
\hline Type of isolate & $\begin{array}{l}\text { Frequency of isolation in } \\
\text { studied units }\end{array}$ \\
\hline Bacillus spp & 12 \\
Aspergillus spp & 8 \\
Penicillium $\mathrm{spp}$ & 7 \\
Aeromonas spp & 6 \\
Staphylococcus spp & 4 \\
\hline
\end{tabular}

Enrichment culture techniques employed for the qualitative recovery of Salmonella, E. coli, Staphylococcus aureus and $P$. aeruginosa demonstrated the absence of these organisms from all items studied. These results corroborate the findings given in Table 2.

\section{DISCUSSION}

This study is the first to focus on the microbiological quality of blister pack tablets manufactured and marketed in Jordan. Products were chosen according to high public demand by the local community; they include anti-diabetic drugs, analgesics and vitamin preparations. The harmonized pharmacopoeial standards stipulate that oral solid dosage forms are required to be free from $E$. coli as a specified organism and should not contain a total bacterial count in excess of $103 \mathrm{CFU} / \mathrm{g}$ [1].

Findings reported in this communication have shown that $72.7 \%$ of the items tested were free from microbial contamination whereas $10.6 \%$ harbored bacteria in counts between 102 and < $103 \mathrm{cfu} / \mathrm{g}$. E. coli was not recovered from any of the products while, Aspergillus and Penicillium spp were present in small numbers in 8 and 7 items, respectively. Candida spp in addition to other pathogenic bacteria such as Salmonella spp were not detected. Therefore, according to the United States Pharmacopoeia [1], all products tested were in compliance with specifications in relation to microbial counts and absence of specified microorganisms.

Microbial counts obtained in this work were different than those reported by Obi and Nwannunu [6] who investigated tablets dispensed to patients by counting and found that all brands they studied harbored microbial count in excess of $105 \mathrm{cfu} / \mathrm{g}$. On the other hand, our results are close to the findings released from Egypt by Gad et al [3]. These authors found that out of 80 tablet dosage forms, $10 \%$ were contaminated with bacteria in counts ranging between 102 and $103 \mathrm{cfu} / \mathrm{g}$, while none contained bacteria in excess of $103 \mathrm{cfu} / \mathrm{g}$, in amazing agreement with the $10.6 \%$ obtained in this work.

Staphylococcus aureus and dermatophytes were the major contaminants recovered from tablets counted to patients in Nigeria [4,6] but none of these organisms was recovered in this study. Another work conducted in Dar es Salam, Tanzania [8] reported that Klebsiella as well as Bacillus spp were the dominant microbial contaminants and this is consistent with our observations in relation to the latter isolate. The isolation of Aeromonas spp from tablets has also been reported [5] and this organism was the only Gram negative bacteria recovered in this investigation. Although members of the family Enterobacteriaceae were not isolated from tablets included in the current work, they have been isolated from tablets by other investigators [4-6]. These authors attributed the presence of contaminants to poor handling during dispensing, repackaging, and / or non-adherence to good manufacturing practice; the later factor could be the cause of contamination in the present study.

Contamination of blister-packed tablets does not occur after the blistering process. Therefore, any contaminant recovered in our investigation must have been acquired during manufacture. Bacillus spp might have gained access to tablets from the environment in which these products were manufactured as these organisms have been commonly found in soil, dust and air $[9,10]$. Spores of fungi are usually found in the atmosphere and thus their presence might be attributed again to the production environment. Staphylococcus spp are normal flora of the skin and are usually incriminated as contaminants of production equipment as well as raw materials. Therefore, their probable source in the tablets studied could have been one or a combination of these sources. Aeromonas spp are usually isolated from water $[11,12]$, but due to the fact that little moisture, if at all is available in tablets, one would expect that their presence may well be due to the use of contaminated water for the cleaning of production equipment. Thus, it can be concluded that pharmaceutical companies in Jordan should pay more attention to the air in the working environment and to the validation of cleaning procedures followed in the production premises.

Trop J Pharm Res, February 2014; 13(2): 264 
Production of tablets is usually conducted in areas classified in current GMP as class D and this category permits the presence of large amount of particles in the premises. Microorganisms including fungal spores have the tendency to adhere to these particles and ultimately settle down in or on the product during the production process. This may explain why many of the contaminants encountered in our investigated products were air borne. The recovery of small numbers of contaminants in the tablets studied might be attributed in part to the low water activity in these products which is usually 0.6 [13]. This low water activity is inhibitory to the growth of most microorganisms. The harsh procedures typically used in the processing of tablets are also detrimental factors for microbial growth and probably contributed to the low microbial counts obtained.

Enrichment cultures performed to selectively isolate $S$. aureus, Salmonella spp and $P$. aeruginosa revealed the absence of these organisms from the brands studied. The absence of the later two organisms is in agreement with most published literature but $S$. aureus has been isolated from tablets by many investigators [3,4]. The explanation to this might be due to the lack of personnel hand interference in the production process or the appropriate personal hygiene followed by the Jordanian industry.

Microbial contamination of tablets is generic to all products and is not confined to a specific item with certain active ingredient (Tables 2 and 3 ). Lovastatin and ibuprofen containing tablets were the only products that were found to be free from contaminants. In this context it should be said that these products were manufactured by two companies whose brands were not found to be contaminated and this may suggest either compliance with GMP or the addition of preservatives into tablet formulations as precautionary measure. It is pertinent to say that none of the manufacturing companies stated the incorporation of preservatives in their products but this is not usually considered as offensive. To rule out the interference of preservatives that might have been included in the formulations studied, preservative neutralizers were added into the recovery medium. Efficacy of the neutralization procedure was confirmed and hence, low numbers recorded were genuine results and were not influenced by the use of faulty techniques.

Microbial count between > 102 and < 103/g was registered for 6 brands belonging to two drug categories manufactured by a single company, further more Aeromonas spp were isolated from the same 6 brands only. These observations suggest that the firm which produced these products had persistent problems related to manufacturing practices. Had the 6 products been omitted from our investigation, the percentage of brands which contained the highest microbial count (>102 and < 103) would have been reduced to $1.5 \%$.

Batch to batch variation in microbial count was demonstrated in the products of two companies. This was deduced from the variation in total bacterial count obtained for the 3 items purchased with different batch numbers. Deviation from the mean count was statistically significant $(p<0.5)$. Thus, this variation indicated the inconsistency of the two firms in the implementation of GMP. In fact, batch to batch variation in the microbiological quality of finished pharmaceutical products has received little attention and therefore our findings cannot be compared with other studies.

\section{Limitation of the study}

Most contaminants detected in tablets investigated herein were either air-borne or water-borne. Therefore, it was deduced that control of air quality and adequate cleaning procedures in the manufacturing premises could improve the microbiological quality of tablets produced by Jordanian firms. This is an assumption which could have been a solid evidence, had we been able to carry out the research described in conjunction with in-house experiments to determine the quality of air and water used in the companies that produced the brands of tablets studied in this work.

\section{CONCLUSION}

This work has demonstrated the acceptable quality of blister pack tablets manufactured by Jordanian pharmaceutical companies in relation to microbial count and the isolation of specified microorganisms. Contaminants detected were probably due to inadequate monitoring of the ventilation systems and the lack of appropriate cleaning validations. If it were not for the water activity of tablets and the production procedures used in tableting, many of the brands investigated might have fallen short of microbiological allowable limits. Therefore, improvement in the implementation of GMP by pharmaceutical manufacturers in Jordan is imperative. 


\section{REFERENCES}

1. United States Pharmacopoeia. Microbiological Examination of No sterile Products: United States Pharmacopoeia. First Supplement, 2009: pp 39263934

2. Luis Jimenez PDA. Microbial bio burden on oral solid dosage forms. J Pharm Sci Tech 2007; 61: 383399

3. Gad GFM, Ibrahem Aly RA, Ashour MSE. Microbial evaluation of some non-sterile pharmaceutical preparations commonly used in the Egyptian market. Trop J Pharm Res 2011; 10: 437-445

4. Akerele JO, Ukoh GC. Aspects of microbial contamination of tablets dispensed in hospitals and community pharmacies in Benin City, Nigeria. Trop J Pharm Res 2002; 1: 23-28

5. Itah AY, Udokpoh AE, Ofum MU. Bacteriological quality of some pharmaceutical products marketed by drug vendors in Uyo, Nigeria. Afr J Health Sci 2004; 11: 128-133.

6. Obi CN, Nwannunu U. Microbiological analysis of drug tablets from selected outlets Umu ahia, Abia state, Nigeria. Res J Pharmacol 2010; 2: 31-37.

7. Barrow G, Feltham R. Cowan and Steels Manual for the Identification of Medical Bacteria. (Third ed.) 1993, Cambridge University Press, Cambridge.
8. Mugoyela V, Mwambete KD. Microbial contamination of nonsterile pharmaceuticals in public hospital settings. Ther Clin Risk Manag 2010; 6: 443-448

9. Ohsaki Y, Koyano S, Tachibana M, Shibukawa K, Kuroki $M$, Yoshida I, Ito Y. Undetected Bacillus pseudooutbreak after renovation work in a teaching hospital. J Infect 2007; 54: 617-622

10. Gorbushina $A A$, Lazarus $D$, Kort $R$, Schnetger $B$ Brumsack HJ, Schulte A, Broughton WJ, Favet J. Life in Darwin's dust: intercontinental transport and survival of microbes in the nineteenth century. Environ Microbiol 2007; 9: 2911-2922

11. Knochel S, Jeppesen C. Distribution and characteristics of Aeromonas in food and drinking-water in Denmark. Int J Food Microbiol 1990; 10: 317-322.

12. Rusin PA, Rose JB, Haas CN, Gerba CP. Risk assessment of opportunistic bacterial pathogens in drinking water. Rev Environ Contam Toxicol 1997; 152: 57-83

13. Friedel RR, Cundell AM. The application of water activity measurement to the microbiological attributes testing of non-sterile over-the counter drug products. Pharmacopeial Forum 1998; 24: 60876090. 